\title{
The role of incremental peritoneal dialysis among patients on peritoneal dialysis. A longitudinal analysis over 20 years.
}

Joana Eugénio Santos, Rui Silva, Rita Vicente, Iolanda Santos, Miguel Coimbra, David Fiel, Manuel Amoedo, Carlos Pires

Division of Nephrology, Hospital Espírito Santo de Évora, Évora, Portugal

\section{ABSTRACT}

Background: There is an ongoing increasing focus on person-centered individualized dialysis prescription. For this model, incremental peritoneal dialysis has been established as a strategy to start peritoneal dialysis, with an intention to increase the dose of peritoneal dialysis, as a consequence of renal clearance declines. In spite of being broadly accepted, the evidence of non-inferiority of the incremental approach in comparison with full dose peritoneal dialysis is weak. To disclose the possibility and safety of an incremental approach in incident patients, we assessed patients and technique survival (main outcomes) between incremental and full dose peritoneal dialysis. We also compared the effects in the clinical parameters of adequacy, urinary output and peritonitis incidence in both approaches.

Methods: Following a retrospective design, we undertook an observational study in our center over 20 years. We investigated 106 patients divided into two groups, according to initial peritoneal dialysis strategy (incremental or full dose). We used multivariate multinomial model to assess predictors of peritonitis. The main outcomes were studies using a competing risk model.

Results: One year after peritoneal dialysis start, our data disclosed statistically significant differences of phosphatemia and solute removal between full dose and incremental approach, favoring the latter. In an incremental approach, two or more peritoneal infections and drop out to hemodialysis were less usual.

Conclusions: Incremental peritoneal prescription seems to be a good choice to start peritoneal dialysis. Potential benefits and, above all, safety reinforce the adoption of incremental peritoneal dialysis in incident patients as a strategy of individualized care, in compliance with new guidelines.

Key-words: incremental, peritoneal dialysis, peritonitis, residual renal function, technique survival

\section{INTRODUCTION}

Incremental peritoneal dialysis (PD) was first described in the late 1990s. Since then, the definition used in studies has varied wildly ${ }^{1}$. Recently, incremental dialysis has been established as a strategy, with a clear intention to increase the dose of PD, as a consequence of renal clearance declines or onset of uremic symptoms. The initial prescription should be lower than standard "full-dose" PD, and the initial peritoneal clearance should be lower than the individualized clearance goal ${ }^{2}$.

In 2006, the International Society for Peritoneal Dialysis (ISPD) published a guideline, primarily focusing on targets for small solute removal and ultrafiltration. However, the relationship between small solute clearance and clinical outcomes has always been particularly weak, without any impact on dialysis-related morbidity and mortality $^{3}$. Also, health-related quality of life (HRQoL) remains poor concerning the overall population ${ }^{3}$. For this, since 2014, transition of care in chronic kidney disease has received focused attention, with the optimization of other dimensions of dialysis delivery accepted nowadays. These include quality of life, psychological burden, inflammation and malnutrition, which can improve patient outcomes with a paradigm shift from a one-size-fits-all approach to a goal-directed dialysis ${ }^{4}$
The concept of incremental PD is inherent to new ISPD recommendations, allowing for an individualized and person-centered prescription, providing better quality of life, fewer exchanges and a smaller solution storage space, something which is often cited as a drawback of $P D^{5,6}$. Although some authors have claimed potential clinical advantages using an incremental approach, the studies are few and heterogeneous ${ }^{7-10}$. Our purpose is to show the possibility of incremental approach without risks for patients. As such, we followed a retrospective design, focused on the comparison between incremental and full-dose PD strategies. The authors believe that the results of this study may reinforce the adoption of an incremental approach for patients who initiate PD.

\section{METHODS}

\section{General Design and Definitions}

Following an observational and retrospective design, we assessed demographic, clinical and analytical data from patients who started PD to address end-stage renal disease (ESRD), in our center, between January 1999 and December 2018.

Our main objective was to disclose the chance of an incremental approach when patients began peritoneal dialysis. For this purpose, we 
used the definition of Incremental PD according to the 1997 NKF-DOQI clinical practice guidelines for peritoneal dialysis adequacy ${ }^{11}$. So, we consider the incremental approach the start of PD on continuous ambulatory peritoneal dialysis (CAPD) using three 1.5-2 L dwells daily, seven days a week. Conversely, we defined full-dose PD prescription as CAPD with 4 or more dwells daily. We excluded patients on automated peritoneal dialysis (APD) because the incremental prescription is not established in this strategy?

The study complied with the principles of the Declaration of Helsinki and the ethical requirements of our center for retrospective observational studies.

\section{Study Population}

For this study, we recruited all patients starting PD in our unit for ESRD treatment, between the $1^{\text {st }}$ January of 1999 and the $31^{\text {st }}$ December of 2018. The follow-up was closed on the $31^{\text {st }}$ December of 2019 . We excluded from the analysis patients $<18$ years of age, PD urgent start, patients with a follow up on PD $<1$ year, patients on APD and patients who were not PD first. Finally, we also excluded patients with unsuitable clinical records.
PD patients were assigned preferably to an incremental prescription when they had a significant residual renal function (RRF) and a full dose of peritoneal clearance was not immediately required. PD prescription was adjusted to a full dose PD regimen following renal clearance declined or onset uremic symptoms.

\section{Study Variables and strategy of analysis}

We reviewed manual medical charts and the hospital's electronic database to collect demographic, clinical and analytical data. Clearances were measured as recommended by international guidelines ${ }^{12,13}$. Overhydration was obtained by multifrequency impedance with $\mathrm{BCM}^{\circledR}$ Monitor.

For our study, we explored:

1) Patients' features related to incremental prescription;

2) Differences between patients on incremental and full dose PD, according to clinically and analytical adequacy;

3) Outcomes of both approaches: RRF, peritonitis incidence, patient survival and technique survival.

\section{Figure 1}

Strobe diagram explaining the size of the sample and outcomes.

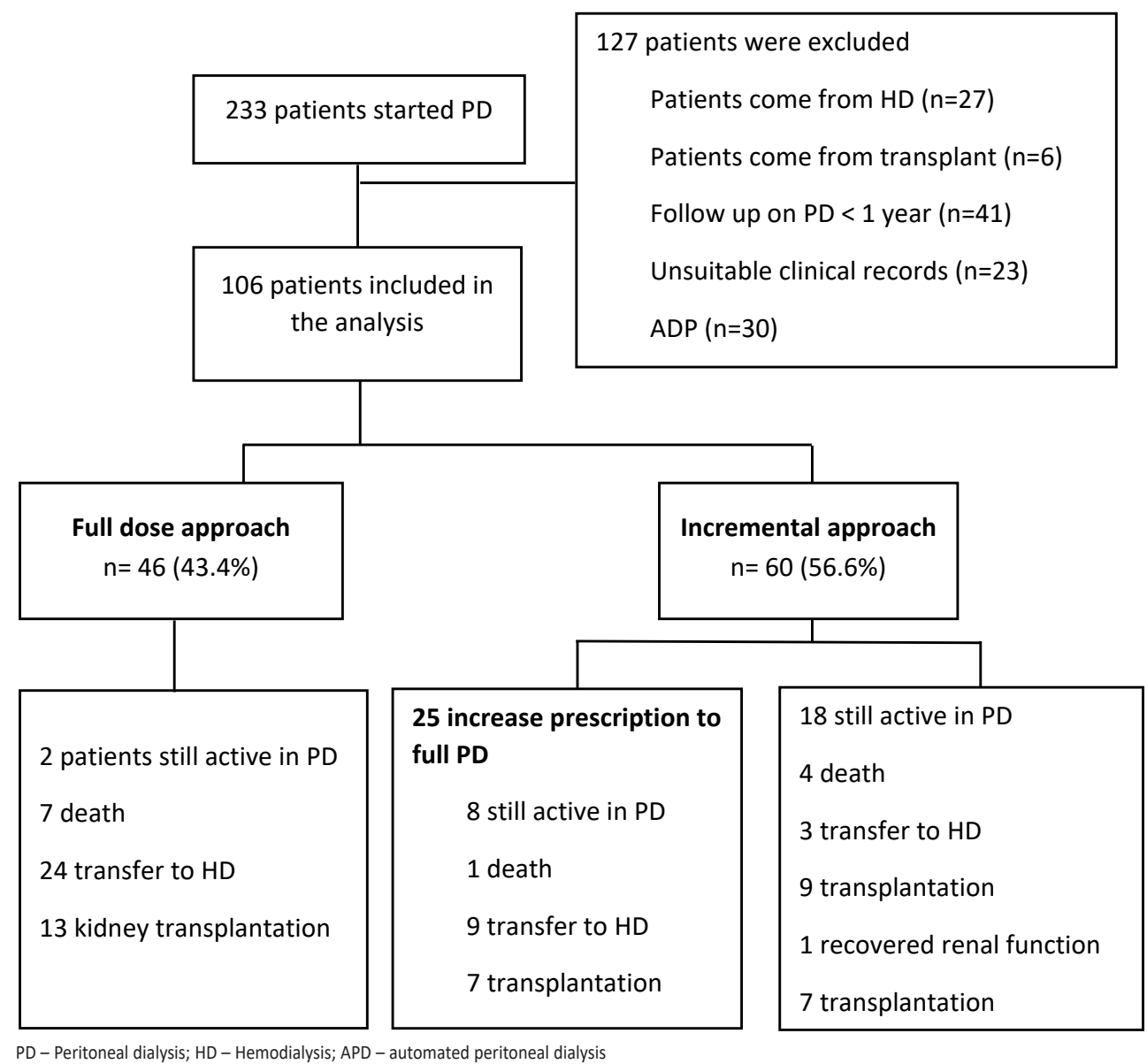

PD - Peritoneal dialysis; HD - Hemodialysis; APD - automated peritoneal dialysis 


\section{Statistical analysis}

Univariate comparisons between groups were performed resorting to the Pearson chi-square test and the t-test or Mann-Whitney $U$ test, under normality assumption, for categorical data and continuous variables, respectively. We used non-parametric paired tests to compare rates of RRF decline. To assess the risk of incremental prescription in the occurrence of peritonitis, we used a multiple binary logistic regression complemented with a multinomial model. Time to event analysis for incremental longevity and technique or patient survival was performed resorting to Kaplan-Maier estimates and a multivariate Cox proportional hazards model. An alternative competing risks model was obtained to give robustness to our results. We used the $\mathrm{R}$ project ${ }^{\circledR}$ software for statistical analysis, with an assumed significance level of $5 \%$.

\section{RESULTS}

\section{Population Overview}

During the study period, 233 patients started PD in our center. From those, 127 patients did not fulfil the study criteria, so we included 106 patients in our analysis (Figure 1).

In our population, there was a minor predominance of the male gender, $56(53 \%)$, with a mean age of $49.1 \pm 14.2$ [range $21-79$ ] years. A quarter of the patients were diabetic (8\% type 1 and $16 \%$ type 2). The leading causes of ESRD were chronic glomerulonephritis, 34 (32\%) and diabetic nephropathy, 20 (19\%). At the end of the study, 36 patients (34\%) were transferred to hemodialysis and 29 patients $(27 \%)$ were transplanted. As a whole, there were 12 deaths (11\%), one patient recovered renal function and 28 patients $(27 \%)$ were still active in PD. The mean follow-up was approximately 4 years (45.1 \pm 24.6 [12 - 105] months).

\section{Incremental prescription}

The series included 60 (57\%) patients under an incremental approach. Table I compares the demographic and clinical characteristics of incremental PD and full dose PD. More patients in incremental PD were female (62\% vs $28 \%, p<0.001 *$ ) and had a better residual renal function, represented by higher urinary output $(1225 \mathrm{~mL}$ IQR[900;1620] vs 700mL IQR[550;1200], $\left.p=0.001^{*}\right)$ and glomerular filtration rate $\left(6.3 \mathrm{~mL} / \mathrm{min} / 1,73 \mathrm{~m}^{2} \mathrm{IQR}[4,4 ; 8,7]\right.$ vs $3.6 \mathrm{~mL} / \mathrm{min} / 1.73 \mathrm{~m}^{2}$ $[2.6 ; 5.6], \mathrm{p}<0.001 *)$. The decade of PD start was also significant, as $82 \%$ of the patients who started PD in the last decade began with an incremental approach, against only $18 \%$ who had begun in the previous decade $(p<0.001 *)$. There were no significant differences between age, etiology of kidney disease, presence of diabetes or anthropomorphic characteristics.

PD adequacy was evaluated regularly according to international guidelines. Table II displays some clinical parameters of adequacy, in the first evaluation after PD start and after a 12-month follow-up. As expected, after one year, the Incremental group still had better RRF and higher solute removal (Kt/V $2.37 \pm 0.59$ vs $2.14 \pm 0.66, p=0.033^{*}$ )

\section{Table I}

Demographic and clinical differences according to study group

\begin{tabular}{|c|c|c|c|}
\hline & Full dose PD & Incremental PD & $p$ value \\
\hline Age (years) & $48.7 \pm 15.2$ & $49.4 \pm 13.6$ & 0.807 \\
\hline Gender (females) (\%) & $13(28)$ & $37(62)$ & $0.001^{*}$ \\
\hline \multicolumn{4}{|l|}{ Kidney disease (\%) } \\
\hline Glomerular & $17(37)$ & $17(28)$ & \multirow{5}{*}{0.760} \\
\hline Interstitial & $2(4)$ & $5(8)$ & \\
\hline Hypertension & $5(11)$ & $10(17)$ & \\
\hline Diabetic nephropathy & $9(20)$ & $11(19)$ & \\
\hline Other/Unknown & $13(28)$ & $17(28)$ & \\
\hline Diabetes (\%) & $10(22)$ & $15(25)$ & 0.872 \\
\hline $\operatorname{BSA}\left(\mathrm{m}^{2}\right)$ & $1.76 \pm 0,18$ & $1.70 \pm 0.18$ & 0.108 \\
\hline Body mass index $\left(\mathrm{Kg} / \mathrm{m}^{2}\right)$ & $24.8 \pm 3.3$ & $24.7 \pm 3.7$ & 0.898 \\
\hline $\mathrm{GFR}^{1}\left(\right.$ per $\mathrm{mL} / \mathrm{min} / 1.73 \mathrm{~m}^{2}$ ) & $3.6[2.6 ; 5.6]$ & $6.3[4.4 ; 8.9]$ & $<0.001^{*}$ \\
\hline Urinary output ${ }^{1}(\mathrm{~mL})$ & $700[550 ; 1200]$ & $1225[900 ; 1625]$ & $0.001^{*}$ \\
\hline \multicolumn{4}{|l|}{ PD start (\%) } \\
\hline $1999-2008$ & $31(67 \%)$ & $11(18 \%)$ & \multirow{2}{*}{$<0.001^{*}$} \\
\hline $2009-2018$ & $15(33 \%)$ & $49(82 \%)$ & \\
\hline
\end{tabular}

${ }^{1}$ Excluding anuric patients.

Figures denote mean values \pm standard deviation, median with interquartile range (numerical variables) or absolute numbers (\%) (categorical variables). Comparison by $\chi 2$ distribution, $t$-test and one-way ANOVA.

PD - Peritoneal dialysis; BSA - Body Surface Area; GFR - Glomerular Filtration Rate

\section{Table II}

Clinical parameters of adequacy at PD start and after 12 months

\begin{tabular}{|c|c|c|c|}
\hline & Full dose PD & Incremental PD & $p$ value \\
\hline \multicolumn{4}{|l|}{ Hemoglobin (g/dL) } \\
\hline At the beginning & $11.2 \pm 2.1$ & $11.5 \pm 1.8$ & 0.612 \\
\hline After 12 months & $10.9 \pm 2.1$ & $11.4 \pm 1.7$ & 0.309 \\
\hline \multicolumn{4}{|l|}{ Albumin (g/dL) } \\
\hline At the beginning & $3.7 \pm 0.5$ & $3.5 \pm 0.4$ & 0.066 \\
\hline After 12 months & $3.5 \pm 0.6$ & $3.6 \pm 0.4$ & 0.308 \\
\hline \multicolumn{4}{|l|}{ Phosphate (mg/dL) } \\
\hline At the beginning & $4.8 \pm 1.1$ & $4.4 \pm 1.1$ & 0.096 \\
\hline After 12 months & $5.2 \pm 1.2$ & $4.6 \pm 0.7$ & $0.018^{*}$ \\
\hline \multicolumn{4}{|l|}{ Overhydration (L) } \\
\hline At the beginning & $2.2 \pm 2.5$ & $1.5 \pm 1.9$ & 0.359 \\
\hline After 12 months & $1.3 \pm 1.8$ & $0.6 \pm 1.3$ & 0.196 \\
\hline \multicolumn{4}{|c|}{$\mathrm{GFR}\left(\mathrm{mL} / \mathrm{min} / 1.73 \mathrm{~m}^{2}\right)$} \\
\hline At the beginning & $4.5 \pm 2.9$ & $6.5 \pm 3.2$ & $0.001 *$ \\
\hline After 12 months & $3.5 \pm 3.2$ & $5.7 \pm 3.2$ & $0.001^{*}$ \\
\hline \multicolumn{4}{|l|}{ Total weekly Kt/V } \\
\hline At the beginning & $2.30 \pm 0.59$ & $2.44 \pm 0.58$ & 0.204 \\
\hline After 12 months & $2.14 \pm 0.66$ & $2.37 \pm 0.59$ & $0.033^{*}$ \\
\hline \multicolumn{4}{|l|}{ Urinary Output (mL) } \\
\hline At the beginning & $700[550-1200]$ & 1225 [900 - 1625] & $0.001 *$ \\
\hline After 12 months & $600[205-1215]$ & 1000 [740 - 1425] & $0.001 *$ \\
\hline
\end{tabular}

Figures denote mean values \pm standard deviation. Comparison t-test or Mann-Whitney $\mathrm{U}$ test, according to normality assumption.

PD - Peritoneal dialysis; GFR - Glomerular Filtration Rate

which certainly contributed for better phosphatemia $(4.6 \pm 0.7 \mathrm{mg} / \mathrm{dL}$ vs $\left.5.2 \pm 1.2 \mathrm{mg} / \mathrm{dL}, \mathrm{p}=0.016^{*}\right)$ and lower overhydration $(0.6 \pm 1.3 \mathrm{~L}$ vs $1.3 \pm 1.8 \mathrm{~L}, \mathrm{p}=0.196)$. 
During the follow-up period, to achieve clearance and therapy goals, 25 patients $(42 \%)$ had a peritoneal prescription increase to full-dose, although only three patients $(5 \%)$ during the first year. At the end of the study, 18 patients (30\%) were still in incremental PD, while 17 patients (28\%) finished PD therapy during the incremental approach: 9 patients received a kidney transplant, 4 patients died, 3 patients dropped out to hemodialysis and one patient recovered renal function. Censoring for PD drop out to hemodialysis, death, kidney transplant and renal function recovery, the median time of Incremental PD prescription was 53.2 months [IC 95\% $34.4-92.6$ ] and one, two and three-year longevity probabilities were $95 \%, 85 \%$ and $56 \%$, respectively.

\section{Residual Renal Function Decline}

During the first year, twelve individuals became anuric, three of them from the Incremental group. When we analyzed diuresis as a surrogate marker for the RRF, we could observe a significant decline in both groups. The mean decline during the first year was $208 \mathrm{~mL}$ $\left(p=0.004^{*}\right)$ in the incremental group, and $237 \mathrm{~mL}\left(p=0.008^{*}\right)$ in the full-dose group. Comparing GFR also showed similar significant losses in both groups, as the mean reduction for the incremental group was $1.2 \mathrm{~mL} / \mathrm{min}\left(p=0.001^{*}\right)$ and for the full-dose group was $0.7 \mathrm{~mL} / \mathrm{min}$ $\left(p=0.024^{*}\right)$.

\section{Peritonitis}

We recorded 108 peritonitis in 60 patients ( 1 episode per 44 months). When we applied a multivariate binary logistic regression with variables such as age, gender, BMI, diabetes or incremental PD, none had a significant protective effect for the occurrence of at least one peritonitis. However, a multivariate multinomial model (with the same variables) showed that the protective effect of Incremental PD is progressive, as revealed by a significant decrease in the probability of 2 or more peritonitis (OR 0.35 [0.14 -0.87$], p=0.046^{*}$ ), whereas only a non-significant reduction occurred for one peritonitis (OR 0.63 [0.24 - 1.68], $p=0.398)$, when compared to peritonitis-free patients (Figure 2).

\section{Technique and Patient Survival}

Until the end of the study and considering hard outcomes, 36 patients (34\%) were transferred to hemodialysis, whereas 12 patients $(11 \%)$ died. For the purpose of this study, no significant differences were recorded for patient survival when analyzing the incremental approach impact. The median time estimate to hemodialysis transfer was 79 months [CI95\% 61-105]. The univariate analysis revealed a significant delay to those on incremental prescription (technique survival at 5 years: $74 \%$ vs $49 \%, p=0.03 *$, log-rank). This result was

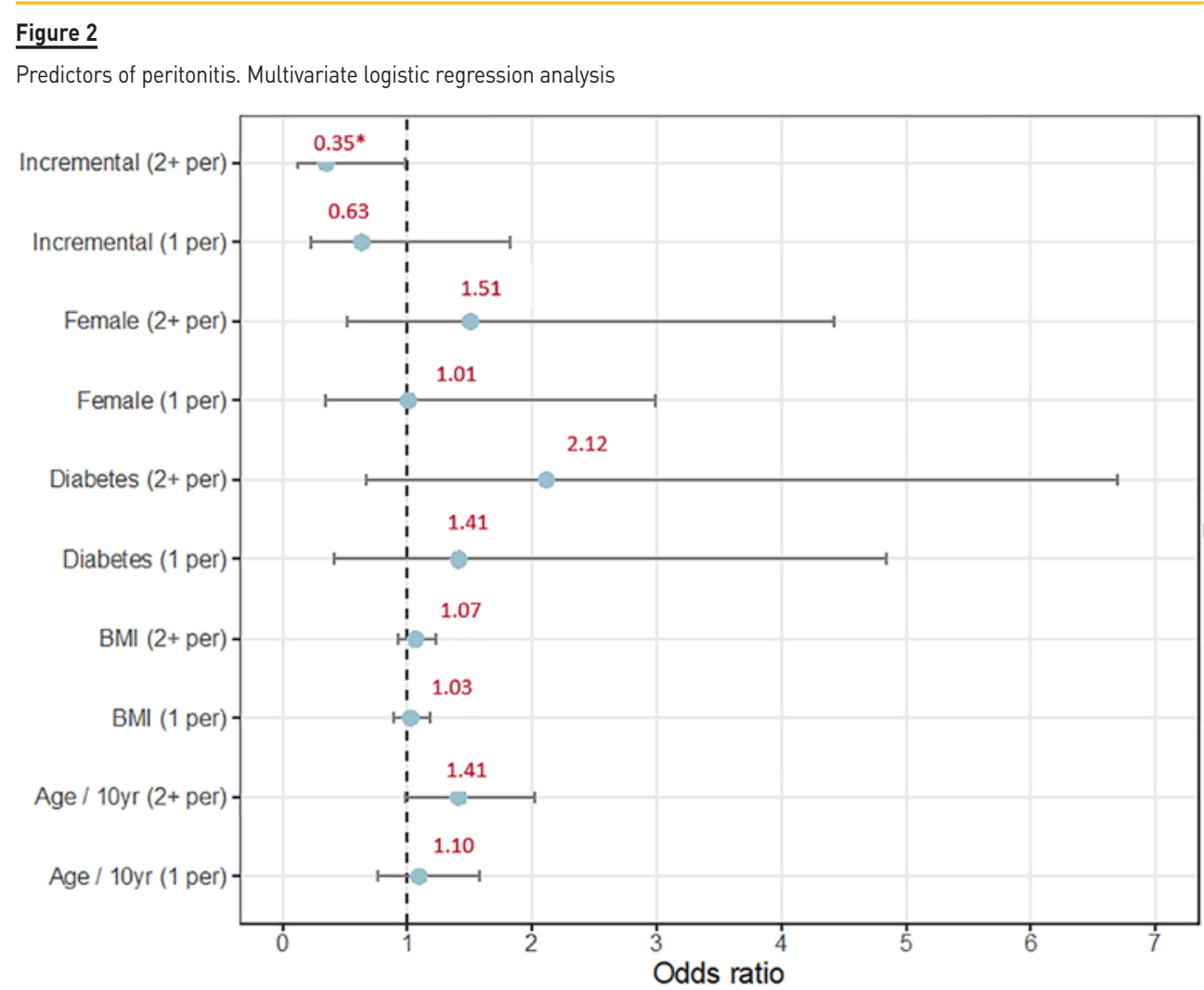

Multivariate multinomial regression analysis. The horizontal line represents confidence intervals and the point in the horizontal line represents the odds ratio. Incremental dialysis had a significant protective effect on the probability of 2 or more peritonitis.

DM - Diabetes mellitus; BMI - body mass index; APD - Automated peritoneal dialysis; yr - years; 1 per - 1 peritonitis; $2+$ per - 2 or more peritonitis. 


\section{Table III}

Predictors of drop out to hemodialysis. Multivariate analysis

\begin{tabular}{l|c|c|c} 
& OR & $95 \% \mathrm{Cl}$ & P value \\
\hline Age (per decade) & 0.97 & $0.75-1.26$ & 0.814 \\
DM & 1.52 & $0.69-3.34$ & 0.303 \\
Albumin (g/L) & 0.89 & $0.38-2.11$ & 0.798 \\
Body mass index (per Kg/m²) & 1.0 & $0.89-1.13$ & 0.999 \\
Peritonitis in the first year & 1.83 & $0.79-4.27$ & 0.158 \\
PD start decade & 1.74 & $0.77-3.91$ & 0.182 \\
GFR (mL/min) & 0.94 & $0.82-1.08$ & 0.401 \\
Incremental approach & 0.41 & $0.19-0.92$ & 0.030
\end{tabular}

Best model. Logistic regression analysis

$\mathrm{OR}$ - Odds ratio; $\mathrm{Cl}$ - Confidence interval; DM - Diabetes mellitus; PD - Peritoneal dialysis; GFR - glomerular filtration rate.

reinforced by a significant protective impact of incremental approach (OR 0.41 [0.19-0.92], $p=0.030^{*}$ ) on the risk of drop out to hemodialysis in a multivariate Cox proportional hazards model (Table III), even with the use of possible variable confounders, such as the occurrence of peritonitis in the first year, RRF or the PD start decade.

Using an alternative competing risks model, the probability of drop out to hemodialysis at 5 years was likewise better for incremental PD patients than for those on full-dose PD ( $19 \%$ vs $38 \%, p=0.033 *)$. For the other events of the analysis (Table IV) there were no significant differences, as the 5 -year probability for death was $9 \%$ vs $13 \%$ ( $p=$ $0.423)$, and for transplant was $22 \%$ vs $20 \%(p=0.835)$.

\section{DISCUSSION}

According to our results, incremental peritoneal dialysis was associated with lower rates of two or more peritonitis and a significant delay in technical failure and drop out to hemodialysis.

In the past, the incremental approach was often mistaken for a way to start dialysis earlier ${ }^{14}$. The potential benefits of this modality, including improved quality of life, reduced glucose exposure, better peritonitis-free survival and longer preservation of RRF, along with the recognition of the modern concept of individualized prescription, have widespread this strategy as a way to start PD worldwide ${ }^{15}$.
However, few observational and randomized trials confirmed these advantages as well as the positive effects on mortality and technique failure.

In our population, females, patients with higher RRF (higher GFR and UO) and patients who began PD recently, were risk factors to receive more often the object of an incremental strategy. While RRF affected the clinical decision of patient allocation (incremental approach vs full dose PD), the unintentional impact of gender can be explained by a lower urea distribution volume in women than men, achieving higher $\mathrm{Kt} / \mathrm{V}$ with fewer daily exchanges ${ }^{16}$.

Phosphate plays a pivotal role in the development of secondary hyperparathyroidism and it is a significant predictor of cardiovascular mortality, together with fluid overload ${ }^{17,18}$. On PD, phosphate balance is complex, depending upon RRF and peritoneal phosphate clearance. After one year, our study found lower levels of phosphatemia in patients under an incremental strategy in comparison with patients under full dose PD. As peritoneal phosphate clearance is slower than urea and creatinine clearance, longer exchanges such as those which occur in an incremental approach, may provide an advantage for phosphate clearance ${ }^{19}$. Despite this, we know that superiority, in phosphate control, is attributable also to better RRF in an incremental approach.

In the last 20 years, there has been a marked decline in peritoneal infections (PIs) after the introduction of Y-set, double bag systems and prophylactic antibiotic before PD catheter insertion ${ }^{20,21}$. Nevertheless, PIs remain a significant source of morbidity, technique failure and mortality among PD patients ${ }^{22,23}$. Even though many studies have identified controversial non-modifiable and modifiable predictors of peritonitis ${ }^{24-26}$, exit-site and catheter-tunnel infections were consistently considered major predisposing factors, favoring recommendations for early peritoneal catheter insertion and accurate management of Staphylococcus aureus carriage, with prophylactic antibiotic use to avoid $\mathrm{Pls}^{27,28}$. On the other hand, the number of exchanges seems to be also a critical determinant of peritonitis ${ }^{29}$. In this context, this study showed a significantly lower risk of two or more peritonitis incidence with an incremental approach, perhaps due to less frequent connections and consequent inferior touch contamination. One study that similarly compares the two approaches did not show statistically significant differences, although patients were preferably treated with APD rather than with CAPD ${ }^{9}$. However, similarly to our results, a study

\section{Table IV}

Technique or patient survival

\begin{tabular}{|c|c|c|c|c|c|c|}
\hline Event & Variable & $\begin{array}{c}\text { Hazard p } \\
\text { (36 months) }\end{array}$ & $\begin{array}{c}\text { Hazard p } \\
\text { (60 months) }\end{array}$ & HR & $95 \% \mathrm{Cl}$ & $P$ value \\
\hline \multirow{2}{*}{ Death } & Full dose prescription & $7 \%$ & $13 \%$ & \multirow{2}{*}{0.62} & \multirow{2}{*}{$0.20-1.98$} & \multirow{2}{*}{0.423} \\
\hline & Incremental & $4 \%$ & $9 \%$ & & & \\
\hline \multirow{2}{*}{ Transfer to HD } & Full dose prescription & $17 \%$ & $38 \%$ & \multirow{2}{*}{0.47} & \multirow{2}{*}{$0.23-0.44$} & \multirow{2}{*}{$0.033^{*}$} \\
\hline & Incremental & $14 \%$ & $19 \%$ & & & \\
\hline \multirow{2}{*}{ Transplant } & Full dose prescription & $14 \%$ & $20 \%$ & \multirow{2}{*}{1.09} & \multirow{2}{*}{$0.52-1.25$} & \multirow{2}{*}{0.835} \\
\hline & Incremental & $16 \%$ & $22 \%$ & & & \\
\hline
\end{tabular}

Competing Risks Models. Risk of drop-out to hemodialysis, death and transplantation between incremental and full PD approach

PD - Peritoneal dialysis; TX - kidney transplantation; HR - Hazard ratio 
that compared a regime of 3 and 4 exchanges showed a tendency towards lower susceptibility for peritonitis in patients undergoing 3-exchange ${ }^{7}$.

Over the years, the relevance of RRF and urinary output (UO) as favorable prognostic factors on morbidity, mortality, and quality of life has grown ${ }^{30}$. Apart from solutes clearance, RRF maintains fluid balance and contributes to essential endocrine functions, including secretion of erythropoietin and synthesis of 1.25-dihydroxycholecalciferol. Strategies aimed to preserve RRF and $U O$ as biocompatible solutions and renin-angiotensin-aldosterone system blockage are of paramount importance to dialysis patients ${ }^{31-33}$. The incremental approach is associated with lower glucose exposure because patients received fewer exchanges and often one icodextrin exchange could be a strategy to preserve RRF and UO. However, our study did not show this protective effect.

Previous studies notwithstanding, at present, technique and patient survival associated with a better quality of life are the most critical challenges in peritoneal dialysis. The widespread use of PD has been limited due to some reluctance of patients and physicians to choose this dialytic modality, traditionally associated with early technique failure ${ }^{34}$. Some reports showed similar results for technique failure and patient survival among patients dialyzed with 3 or 4 exchanges ${ }^{35,36}$. In our study, the risk of drop out to hemodialysis between patients under an incremental approach was lower than in full dose PD $\left(p=0.033^{*}\right)$. Only incremental strategy was associated with better outcomes in technique failure and consequent drop out to hemodialysis. Although we did not evaluate total glucose exposure, the lower risk of drop out to hemodialysis in patients who begin PD under an incremental approach could be due to peritoneal membrane ultrastructure transformations by glucose and GPD susceptibility 37,38 . In our study, the occurrence of peritonitis did not show any significant relation with technique failure. These results are in concordance with previous studies, although they have not assessed the effect of 3-PD exchange per day.

There are several limitations to our study. First, this was a retrospective single-center study, which causes a potential bias due to allocation based in RRF. Second, the sample size is small. Third, in the incremental group, there was a presumable influence of better GFR and urinary output on phosphate control and solute removal and not only the incremental approach itself. Fourth, some variables with potential impact on technique survival, such as glucose exposure, $\mathrm{PTH}$ and peritoneal protein clearance, were not recorded. Additionally, other variables could enrich our study, such as measurements concerning quality of life. On the other hand, significant strengths include the high quality of our database, which allowed us to study many variables, as well as technique and patient survival and long-term follow-up. Despite this, we cannot exclude the possibilities of bias by PD technique and solution improvment over time.

In summary, patients on the incremental approach had lower levels of phosphatemia and higher solute removal measured by Kt/V associated with longer exchanges and lower urea distribution volume in females, but also higher GFR and UO. Finally, they had higher technique survival, lower risk of drop out to hemodialysis and lower rate of two or more peritonitis linked to fewer exchanges. We are sure that higher
GFRs influenced these parameters in the incremental approach. Thus we conclude that incremental dialysis can be safe and a reasonable strategy in PD incident patients

Disclosure of potential conflicts of interest: none declared.

\section{References}

1. KD, N. Rationale for early incremental dialysis with continuous ambulatory peritoneal dialysis. Nephrol Dial Transplant. 1998; 13(6):117-119.

2. Blake PG, D.J., Davies SJ. Incremental peritoneal dialysis. Perit Dial Int. 2020; 17(896860819895362).

3. Perl J, D.L., Bargman JM, Browne T, Charytan DM, Flythe JE et al. The use of a multidimensional measure of dialysis adequacy-moving beyond small solute kinetics. Clin J Am Soc Nephrol. 2017; 12(5):839-847.

4. Chan CT, B.P., Dember LM, Gallieni M4, Harris DCH, Lok CE. Dialysis initiation, modality choice, access, and prescription: conclusions from a Kidney Disease: Improving Global Outcomes (KDIGO) Controversies Conference. Kidney Int. 2019; 96(1):37-47.

5. Brown EA, B.P., Boudville N, Davies S, de Arteaga J, Dong J. International Society for Peritoneal Dialysis practice recommendations: prescribing high-quality goal-directed peritoneal dialysis. Perit Dial Int. 2020; 21(896860819895364).

6. Sukul N, Z.J., Fuller DS, Karaboyas A, Bieber B, Sloand JA et al. Patient-reported advantages and disadvantages of peritoneal dialysis: results from the PDOPPS. BMC Nephrol. 2019; 20(1):116.

7. Yan H, F.W., Lin A, Cao L, Ni Z, Qian J. Three versus 4 daily exchanges and residual kidney function decline in incident CAPD patients: a randomized controlled trial. Am J Kidney Dis. 2017; 69(4):506$-513$.

8. Obi Y, S.E., Rhee CM, Ravel V, Amin AN, Cupisti A. Incremental hemodialysis, residual kidney function, and mortality risk in incident dialysis patients: a cohort study. Am J Kidney Dis. 2016; 68(2):256-265.

9. Sandrini M, V.V., Valerio F, Ravera S, Manili L, Zubani R, Lucca BJ, Cancarini G. Incremental peritoneal dialysis: a 10 year single-centre experience. J Nephrol. 2016; 29(6):871-879.

10. Ankawi GA, Woodcock NI, Jain AK, Garg AX, Blake PG. The Use of Incremental Peritoneal Dialysis in a Large Contemporary Peritoneal Dialysis Program. Can J Kidney Health Dis;3:2054358116679131.

11. NKF-DOQI clinical practice guidelines for peritoneal dialysis adequacy. National Kidney Foundation. Am J Kidney Dis. 1997; 30(2):S67-S136.

12. Group, P.D.A.W. Clinical practice guidelines for peritoneal dialysis adequacy. Am J Kidney Dis. 2006; 48(1):S98-S129.

13. Blake PG, B.J., Brimble KS, Davison SN, Hirsch D, McCormick BB. Clinical Practice Guidelines and Recommendations on Peritoneal Dialysis Adequacy 2011. Perit Dial Int. 2011; 31(2):218-239.

14. Rosansky SJ, C.W., Eggers P, Glassock RJ. Initiation of dialysis at higher GFRs: is the apparent rising tide of early dialysis harmful or helpful? Kidney Int. 2009; 76(3):257-261.

15. De Vecchi AF, S.A., Finazzi S, Colucci P, Ponticelli C. Preliminary evaluation of incremental peritoneal dialysis in 25 patients. Perit Dial Int. 2000; 20(4):412-417.

16. Debowska M, P.R., Ventura MD, Ávila-Díaz M, Prado-Uribe C, Mora C et al. Dialysis adequacy indices and body composition in male and female patients on peritoneal dialysis. Perit Dial Int. 2014; 34(4):417-425

17. Wu M, W.H., Huang X, Ye H, Huang F, Yu X et al. Associations between serum mineral metabolism parameters and mortality in patients on peritoneal dialysis. Nephrology (Carlton). 2019. 24(11):1148-1156.

18. Paniagua R, V.M., Avila-Díaz M, Hinojosa-Heredia H, Méndez-Durán A, Cueto-Manzano A et al. NT-proBNP, fluid volume overload and dialysis modality are independent predictors of mortality in ESRD patients. Nephrol Dial Transplant. 2010; 25(2):551-557.

19. Courivaud C, D.A. Phosphate removal by peritoneal dialysis: the effect of transporter status and peritoneal dialysis prescription. Perit Dial Int. 2016; 36(1):85-93.

20. Daly C, C.J., Khan I, Rabindranath KS, Vale L, Wallace SA. Double bag or Y-set versus standard transfer systems for continuous ambulatory peritoneal dialysis in end-stage kidney disease. Cochrane Database Syst Rev. 2014; 13(8):CD003078.

21. Strippoli GF, T.A., Johnson D, Schena FP, Craig JC. Antimicrobial agents to prevent peritonitis in peritoneal dialysis: a systematic review of randomized controlled trials. Am J Kidney Dis, 2004; 44(4): 591-603

22. Ye H, Z.Q., Fan L, Guo Q, Mao H, Huang F et al. The impact of peritoneal dialysis-related peritonitis on mortality in peritoneal dialysis patients. BMC Nephrol. 2017; 18(1):186.

23. Sia CSB, P.E., Tregaskis P, Walker RG, Wilson SG. The longitudinal effects of peritonitis on peritoneal membrane function. Clin Nephrol. 2017; 88(12):311-316.

24. Gadola L, P.C., Dominguez P, Poggio MV, Lungo E, Cardozo C. Risk factors and prevention of peritoneal dialysis-related peritonitis. Perit Dial Int. 2019; 39(2):119-125.

25. Rodríguez-Carmona A, P.-F.M., López-Muñiz A, Ferreiro-Hermida T, García-Falcón T. Correlation between glycemic control and the incidence of peritoneal and catheter tunnel and exit-site infections in diabetic patients undergoing peritoneal dialysis. Perit Dial Int. 2014; 34(6):618-626.

26. Martin LC, C.J., Fernandes N, Divino-Filho JC, Pecoits-Filho R, Barretti P. Brazilian Peritoneal Dialysis Multicenter Study BRAZPD Group., Geographic and educational factors and risk of the first peritonitis episode in Brazilian Peritoneal Dialysis study (BRAZPD) patients. Clin J Am Soc Nephrol. 2011; 6(8):1944-1951.

27. van Diepen AT, T.G., Jassal SV. The association between exit site infection and subsequent peritonitis among peritoneal dialysis patients. Clin J Am Soc Nephrol. 2012; 7(8):1266-1271. 
28. Santos C, P.-F.M., Rodríguez-Carmona A, Calvo-Rodríguez M, López-Muñiz A, López-Calviño B et al. Identification of targets for prevention of peritoneal catheter tunnel and exit-site infections in low incidence settings. Perit Dial Int. 2016; 36(1):43-51.

29. Bieber SD, B.J., Golper TA, Teitelbaum I, Mehrotra R. Comparative outcomes between continuous ambulatory and automated peritoneal dialysis: a narrative review. Am J Kidney Dis. 2014; 63(6):1027-1037.

30. Termorshuizen F, K.J., Dekker FW, van Manen JG, Boeschoten EW, Krediet RT. NECOSAD Study Group, The relative importance of residual renal function compared with peritoneal clearance for patient survival and quality of life: an analysis of the Netherlands Cooperative Study on the Adequacy of Dialysis (NECOSAD)-2. Am J Kidney Dis. 2003; 41(6):1293-1302.

31. Zhang L, Z.X., Fu P, Wu HM. Angiotensin-converting enzyme inhibitors and angiotensin receptor blockers for preserving residual kidney function in peritoneal dialysis patients. Cochrane Database Syst Rev. 2014; 23(6):CD009120.

32. Htay H, C.Y., Pascoe EM, Darssan D, Hawley C, Johnson DW. balANZ trial investigators, Predictors of Residual Renal Function Decline in Peritoneal Dialysis Patients: The balANZ Trial. Perit Dial Int. 2017; 37(3):283-289.

33. van Olden RW, G.H., Struijk DG, Krediet RT, Arisz L. Acute effects of high-dose furosemide on residual renal function in CAPD patients. Perit Dial Int. 2003; 23(4):339-347.

34. Mehrotra R, D.O., Davies SJ, Johnson DW. The current state of peritoneal dialysis. J Am Soc Nephrol. 2016; 27(11):3238-3252.

35. Lo WK, J.Y., Cheng SW, Cheng IK. Survival of CAPD patients in a center using three two-liter exchanges as standard regime. Perit Dial Int. 1996; 16(1):S163-S166.
36. Szeto CC, Lai KN, Yu AW, Leung CB, Ho KK, Mak TW, Li PK, Lam CW. Dialysis adequacy of Asian patients receiving small volume continuous ambulatory peritoneal dialysis. Int J Artif Organs. 1997; 20(8):428-435.

37. Liao CT, C.Y., Shiao CC, Hu FC, Huang JW, Kao TW et al. Rate of decline of residual renal function is associated with all-cause mortality and technique failure in patients on long-term peritoneal dialysis. Nephrol Dial Transplant. 2009; 24(9):2909-2914.

38. Bartosova M, Schaefer B, Vondrak K, Sallay P, Taylan C, Cerkauskiene R, Dzierzega M, Milosevski-Lomic G, Büscher R, Zaloszyc A, Romero P, Lasitschka F, Warady BA, Schaefer F, Ujszaszi A, Schmitt CP. Peritoneal Dialysis Vintage and Glucose Exposure but Not Peritonitis Episodes Drive Peritoneal Membrane Transformation During the First Years of PD. Front Physiol. 2019 Apr 2;10:356. doi: 10.3389/fphys.2019.00356.

\section{Correspondence to:}

Joana Margarida Eugénio dos Santos

Nephrology department; Hospital Espírito Santo de Évora

Largo Senhor da Pobreza, 7000-811, Évora

E-mail: joana.eugenio.santos@gmail.com 